\title{
EDITORIAL
}

\section{Poesia e PRÁticas de CITAÇÃo}

Há um conjunto de verbos que bem pode constituir uma breve amostra do vocabulário utilizado recorrentemente pela crítica literária para descrever mecanismos intertextuais, interartísticos e intermediais: apropriar, aludir, citar, colar, coletar, copiar, cortar, cruzar, decupar, deslocar, editar, enxertar, fragmentar, importar, justapor, manipular, mencionar, montar, mover, reaproveitar, reciclar, recontextualizar, reelaborar, reescrever, reler, remixar, remover, reorganizar, repetir, reutilizar, samplear, selecionar e traduzir. É este universo de movimentos textuais que o dossiê do número 32 da Texto Poético convoca para explorar um dos mais importantes recursos da criação literária - a citação. Do texto entendido como um "mosaico de citações" segundo Julia Kristeva, ao cunhar o termo "intertextualidade" nos anos 1960, à "transtextualidade" proposta por Gérard Genette para caracterizar a relação de copresença entre um ou mais textos, a partir de um dado cruzamento de vozes. Da prática do "desvio da citação" observada em Walter Benjamin, que fez do exercício citacional um pilar decisivo de seu pensamento, entendendo a citação como um lugar de origem e de destruição da linguagem, à concepção de "citacionalidade" que Marjorie Perloff desenvolve a partir da dialética do "escrever-através" que caracteriza o trabalho do "gênio não original”. Da noção de onipotência que Antoine Compagnon atribui ao "trabalho da citação", consentindo-o como uma das mais vigorosas formas de deslocamento, à perspectiva de "descontruir e agravar" engendrada por Jean-Michel Maulpoix para descrever a poesia mais recente, que diz aprofundar uma linguagem objetiva citacional. Da apropriação como mote central da "escrita não criativa" proposta por Kenneth Goldsmith à ideia de "escrever sem escrever no século XXI" desenvolvida por Leonardo Villa-Forte. Como se pode ver, da segunda metade do século XX para cá tem sido bastante profícuo, efervescente e complexo o panorama teórico- 
crítico que abrange desde os desdobramentos conceituais acerca da intertextualidade até a diversidade dos procedimentos apropriatórios na escrita.

O dossiê Poesia e práticas de citação mobiliza, dessa forma, vários desses conceitos, abordagens e debates para investigar a importância da citação nos modos de se pensar a poesia, considerando o recurso citacional como mecanismo elementar da criação poética. As formas de citar e os seus efeitos no texto permitem atribuir novos sentidos e conferir possibilidades diversas a textos preexistentes, numa dinâmica que é aqui amplamente perscrutada. De que maneira a citação desempenha um papel estrutural no processo criativo? Como o poeta lê a sua obra enquanto a escreve? E como os mecanismos de autoconsciência da escrita se relacionam com as práticas de leitura de um autor? De que modo o reaproveitamento de materiais textuais alheios ou próprios permite observar escolhas eletivas, olhares críticos e estratégias de criação? Ao acolher, dispersar ou rejeitar textualidades diversas, o poeta evidencia a sua postura poética e ética, assim como também estão nela implicadas as suas experiências de leitura. Investigar como um poeta leu outros autores, convocando a perspectiva de uma leitura ativa, ajuda-nos a compreender não só a obra desse poeta, mas a sua própria visão crítica sobre poesia. Daí que seja tão significativo para entender o processo criativo analisar os vestígios de leitura, o aproveitamento de fragmentos de discursos, a reutilização de frases ou versos, as justaposições textuais e a diluição das hierarquias, o desenvolvimento do pensamento em rede. O diálogo de um texto com textos anteriores, com outras formas de arte, outras mídias fortalece o espaço comparatista que estimula aproximações, conexões e confrontos, inclusive entre obras ou objetos que à partida pareceriam pouco prováveis de se relacionar.

É neste sentido que, sendo a dinâmica de escrita uma dinâmica também de leitura, as citações atuam, no domínio da memória intertextual, como sinapses pelas quais circulam impulsos, energias e esforços criativos, ou ainda como junções que permitem conectar elementos diversos, propagando ou mesmo despoletando o estímulo criativo através 
de conexões em rede. A citação funciona como um elo que viabiliza as mais distintas formas de convívio entre vários elementos. Em latim, citare significa "fazer mover", "colocar em movimento", "fazer passar do repouso à ação" (Compagnon). Se bem repararmos, essa noção está na base que une os verbos coligidos no início deste editorial, apontando para a força da ação, para a energia do ato. Mais do que um gesto, o recurso citacional se estabelece como um ato, ainda que nem sempre consciente. Não por acaso, muitos verbos que são associados ao ato de citação começam com o prefixo "re-", indicando repetição, reforço, reciprocidade ou movimento de regresso - concepções que partilham a ideia de um retorno ao ponto de partida, de uma volta ao início. Por isso, podemos dizer que citar implica sempre uma leitura restitutiva. O que faz lembrar Benjamin, quando diz que a tarefa do historiador materialista é vivificar o presente através da rememoração do passado, assumindo uma forma particular de citação que permite fazer desse passado uma experiência única. Ou quando Compagnon afirma que a citação é uma "rememoração da origem”, por isso não se consegue definir precisamente o seu conceito, mas tão somente anuir que toda prática de escrita e de leitura é já em si um ato de citação.

Com esse horizonte de análise, nos 11 artigos que compõem o dossiê, observaremos de perto esse conjunto de traços que marcam as práticas de citação, atentando para várias formas de conversação entre poetas e livros, filmes, músicas, procedimentos artísticos. Este número, cujo recorte temático ganha múltiplos contornos com os deslocamentos conceituais em torno do autor, do leitor e da obra nas últimas décadas, contempla ainda as relações possíveis de se estabelecer entre a criação poética e a materialidade de seus processos discursivos a partir da paródia, da ironia, da sátira, da alegoria, da colagem, da montagem, entre outras formas de apropriação textual.

Os coautores João Cláudio Arendt e Rafael de Lucena destacam a obra do importante poeta chileno Nicanor Parra, ainda pouco lido no Brasil, analisando, sob a perspectiva da antipoesia, da metapoesia e da ironia, uma seleta de poemas publicados em livros entre 1954 e 1963. Em seguida, Paulo Alberto da Silva Sales discute com viés comparatista, nas 
poéticas da portuguesa Adília Lopes e do brasileiro Carlito Azevedo, a prática da citacionalidade e as referências multivocais nos seus discursos poéticos, explorando uma poética citacional, híbrida e não original, como analisa a crítica americana Marjorie Perloff, em sua conhecida obra O gênio não original: poesia por outros meios no novo século. Os dois poetas lidos apresentam propostas criativas distintas mas evidenciam, sobretudo em seus últimos livros, práticas de citação, de enxertos, incluindo fotografias, fragmentos de textos em língua estrangeira e de diversos gêneros, que se articulam nos poemas. Ainda sobre Carlito Azevedo, o artigo seguinte, assinado em coautoria por Frederico Nogueira Klumb e Franklin Alves Dassie, demonstra o diálogo possível entre as práticas poéticas do brasileiro com as do cineasta Jean-Luc Godard, a partir da ideia de montagem. Para isso, examinam o Livro de Postagem (2016) de Carlito Azevedo e o filme História(s) do cinema, 1988-1998, do cineasta francês.

Os quatro artigos seguintes tratam de poetas portugueses, modernos e contemporâneos, como Ruy Belo e Luis Quintais, ou clássicos, como Camões e Bocage. Sobre esses dois últimos, provocando o encontro entre o incontornável clássico e o pré-romântico insubmisso às academias, Flávia Pais de Aguiar estuda como a referenciação é processo de construção artística fundamental para Bocage em relação ao vate Camões, que é transformado em modelo estético, social e ético. A abordagem da autora vale-se dos "entendimentos aristotélico e horaciano, que norteiam a noção do processo de mimesis [...]”, valorizando a interdiscursividade, o reconhecimento da escrita alheia e os meios de recriação na constituição da própria originalidade da poesia de Bocage, no final do século XVIII. Em relação ao século XX e mesmo XXI, a autora Ana Maria Pereira Soares estuda RuyBelo, com a análise de um excerto do poema A margem da alegria, cotejando-o com a obra de Dominique Saint-Alban, Le roman d'amour des grandes Égéries, para demonstrar o caráter hipertextual da escrita do poeta português que faleceu em 1978, deixando uma obra poética em que a prática citacional e o diálogo com tradições tornam-se mesmo obsessões criativas. Como escreve a autora, "alguns dos mecanismos compositivos utilizados pelo poeta, a sua relação com a influência é de aceitação da sua 
inevitabilidade. No entanto, trata-se de uma aceitação que procura vencer esse ensombramento das vozes antigas sobre o poeta tardio." Também sobre a poética de Ruy Belo, os coautores Adriano Tarra Betassa Tovani Cardeal e Maria Lúcia Outeiro Fernandes destacam, no livro Homem de palavra[s] (1970), o poema Nós os vencidos do catolicismo, a fim de mostrar "algumas das técnicas de intertextualidade mais usadas" pelo poeta ao longo da sua obra lírica: citação, alusão e referência. A abordagem teórica vale-se sobretudo dos críticos literários franceses Julia Kristeva (1941-), Gérard Genette (1930-2018) e Tiphaine Samoyault (1968-). Em relação aos mais contemporâneos ainda em produção, as poéticas de Francisco Alvim e Luís Quintais são analisadas pelas coautores Deyse Moreira e Ida Alves, em perspectiva comparativa, com destaque para a paródia e a alegoria como "procedimentos intertextuais e interartísticos de apropriação, metarrepresentação e refuncionalização", os quais constituem, no âmbito da produção lírica de Brasil e Portugal, um "imaginário apropriado, que tem caracterizado a arte contemporânea.” A mobilização de diferentes práticas intertextuais e interartísticas questionam o trabalho poético entre repetição e transformação.

Na parte final do dossiê, Mayra Moreyra Carvalho, agora no campo da música popular brasileira, convoca Chico Buarque, ao propor "um modo de escuta de duas canções, Pedro pedreiro (1966) e Construção (1971), a partir da relação possível com a poesia dos hispano-americanos César Vallejo e Juan Gelman”. Discute, por essa trilha, como o compositor apropria-se da tradição musical e literária, pondo em movimento criativo as práticas de escuta e leitura. Em contínuo, são publicados mais três artigos: Miguel de Ávila Duarte expõe o seu estudo sobre o compositor, escritor e artista plástico americano John Cage, "citado como precursor da escrita apropriativa contemporânea por Goldsmith (2011)”. Como é explicado no artigo, "trata-se, nas próprias palavras de Cage, de uma 'escrita através [writing through]', recurso fundamental do que denominamos os textos-preparados desse autor: aplicando as regras do mesóstico ou operações aleatórias (chance operations), o compositor produzia um novo texto a partir de palavras, às vezes apenas sílabas e letras, de um texto 
fonte, no qual o sentido e a sintaxe do original comparecem às vezes apenas residualmente". No artigo de Patrícia Lino, com o provocativo título, "Contra a anestesia, a gargalhada corrosiva. Sobre o processo de escrita d'O Kit de Sobrevivência do Descobridor Português no Mundo Anticolonial”, o leitor conhecerá um projeto paródico e altamente crítico de determinadas noções/citações frequentes do pensamento colonial e do debate pós-colonial. Tal projeto é de sua própria autoria, como esclarece: "É sobre este estatuto de independência que $O$ Kit de Sobrevivência do Descobridor Português no Mundo Anticolonial se constrói. Escrito por mim entre 2019 e 2020, publicado em outubro de 2020 em Portugal e no Brasil respetivamente pela Douda Correria e Edições Macondo, e composto por 40 objetos imaginários, O Kit de Sobrevivência do Descobridor Português no Mundo Anticolonial expõe, de modo corrosivo e crítico, as contradições, absurdos e antipatias do discurso colonial português. Estes 40 objetos imaginários são sempre introduzidos pela mesma combinação: uma colagem digital, que apresenta visualmente o utensílio, e dois textos ('o que é'; 'como usar')". O artigo que fecha o dossiê, intitulado "The unsivilized figure as cultural hero of artifice: Suassuna's João Grilo and Twain's Huck Finn", de autoria de Benjamin Chaffin, trata de um inesperado encontro no tempo e espaço entre o escritor brasileiro Ariano Suassuna (19272014) e o escritor norte-americano Mark Twain (1835-1910). A partir dos modelos do "Trickster" e do "pícaro", os dois escritores dão voz a dois personagens "socioeconomicamente marginalizados em regiões carentes", João Grilo e Huck Finn, estabelecendo um par que imita "o contraponto cognitivo entre Dom Quijote de Miguel de Cervantes e Sancho Pança”, com base numa abordagem da teoria cognitiva e psicossocial. Em sua perspectiva, trata-se de "heróis do artifício".

Entre o dossiê e a seção Vária, temos a grande satisfação de publicar uma entrevista com Hans Ulrich Gumbrecht sobre o seu novo livro Prose of the World: Denis Diderot and the Periphery of Enlightenment (Prosa do Mundo: Denis Diderot e a Periferia do Iluminismo), publicado em alemão em outubro de 2020, pela editora Suhrkamp, com previsão de lançamento em inglês em maio de 2021, pela Stanford University Press. No Brasil, a 
obra deverá vir a lume pela Editora Unesp, com tradução de Ana Isabel Soares, mas ainda não há data para a sua publicação. Professor Emérito de Literatura em Stanford, ocupando a cadeira Albert Guérard, foi ainda professor na Universität Konstanz (1971-1974), onde se doutorou em 1971, e nas universidades de Bochum (1975-1982) e de Siegen (19831989), onde fundou o Programa de Pós-Graduação em Humanidades. Em 1989, parte para os Estados Unidos, onde desde então leciona em Stanford nos departamentos de Literatura Comparada, de Francês e Italiano, de Estudos Germânicos e de Culturas Ibéricas e Latinoamericanas. Realizada por Manaíra Athayde, a entrevista ocorreu no Pigott Hall, edifício que abriga os departamentos de literaturas, culturas e línguas da Stanford University, na Califórnia. A longa conversa ocorreu em português, língua de afeto para Gumbrecht, o qual ao longo de sua carreira tem ensinado e apresentado conferências no Brasil e em Portugal. Como o leitor verá, o pensamento dele transita sempre entre línguas e, por isso, o inglês, o alemão, o francês e o espanhol são também convocados. Entre outros tópicos, conversou-se sobre a afinidade entre o estilo intelectual de Diderot e algumas de nossas preocupações no século XXI, a abertura ao mundo e a complexidade dispersiva, a fusão entre software e consciência, o pensamento ecológico e a continuidade da vida humana no planeta. $\mathrm{O}$ leitor certamente ficará bastante interessado sobre o que nos respondeu Gumbrecht.

Por fim, encerrando este número, a seção Vária reuniu três artigos: "Considerações sobre a concepção de metro e ritmo em Castilho", de Paulo Franchetti; "A rua em mim: memória urbana na poesia de Ferreira Gullar e Joãozinho Ribeiro", de Silvana Pantoja dos Santos e "A mão que balança o vero: uma proposta de leitura sobre recepção de arte”, de Luciana Fernandes Ucelli Ramos e Maria Amélia Dalvi Salgueiro. O conhecido ensaísta, crítico, professor e poeta, sempre atento ao texto poético e sua elaboração, destaca na obra do poeta oitocentista António Feliciano de Castilho (1800-1875), tão menosprezado pela Academia do século XX e praticamente ignorado na atualidade, o seu Tratado de Metrificação Portuguesa (1. ed. 1858), para examinar "a dupla determinação do 
ritmo, que se dá pela colisão ou harmonia do metro internalizado com a realização do verso na leitura”. Afastando-se da visão depreciativa sobre o que nos deixou Castilho, Paulo Franchetti destaca pontos originais do pensamento castilhiano sobre o verso e não só, que precisam ser rediscutidos. Já o segundo artigo dessa seção realiza um estudo sobre a escrita da cidade, examinando "o processo de rememoração das ruas em Poema sujo, de Ferreira Gullar, e Paisagem feita de tempo, de Joãozinho Ribeiro”. E o terceiro artigo, fecho da Vária, propõe-se a analisar o papel desempenhado pela arte na cosmovisão dos sujeitos contemporâneos e, para isso, toma como corpus a canção de Chico Buarque de Hollanda, designando-a como "oraliteratura".

Acreditamos, portanto, que este número da Texto Poético cumpre muito bem sua proposta de pensar teórica e criticamente, por diversas perspectivas e com diferentes autores e obras, as práticas citatória, intertextual, interartística e a pluralidade de procedimentos apropriatórios na escrita, discutindo criação, originalidade e transformação. Que os verbos citados no início deste editorial se movimentem nas muitas leituras propostas e que os nossos leitores dialoguem.

Ida Alves ${ }^{1}$ Manaíra Aires Athayde ${ }^{2}$

(Organizadoras)

1 Professora Titular de Literatura Portuguesa do Instituto de Letras da Universidade Federal Fluminense/UFF, Niterói, Rio de Janeiro, Brasil. Docente Permanente do Programa de Pós-Graduação em Estudos de Literatura UFF.

E-mail: idaalves@id.uff.br. Orcid iD: https://orcid.org/0000-0002-6892-7289

2 Pesquisadora visitante (visiting scholar) no Department of Iberian and Latin American Cultures, na Stanford University/SU, Palo Alto, Califórnia, Estados Unidos, e pesquisadora colaboradora do Centro de Literatura Portuguesa da Universidade de Coimbra/UC, Coimbra, Portugal.

E-mail: manaira.athayde@gmail.com. Orcid iD: https://orcid.org/0000-0001-8358-6104 